\title{
Perception of Advance Directive in Thai Women with Cancer: A Qualitative Study
}

\author{
Tharin PHENWAN ${ }^{1, *}$, Patsri SRISUWAN ${ }^{2}$ and Tanongson TIENTHAVORN ${ }^{3}$ \\ ${ }^{I}$ School of Medicine, Walailak University, Nakhon Si Thammarat 80160, Thailand \\ ${ }^{2}$ Department of Family Medicine, Phramongkutklao Hospital, Bangkok 10400, Thailand \\ ${ }^{3}$ Department of Community and Military Medicine, Phramongkutklao College of Medicine, \\ Bangkok 10400, Thailand
}

('Corresponding author's e-mail: tharin.ph@wu.ac.th)

Received: 8 March 2017, Revised: 29 September 2017, Accepted: 17 October 2017

\begin{abstract}
Advance Directive (AD) is a medical agreement to ensure that patients' autonomy is respected. In Thailand, there has been Health Act Legislation to promote the use of a living will, a form of AD, since 2007. However, there is no assessment of its practicability yet. The objective of this study was to explore perceptions and attitudes to living wills by women who were diagnosed with cancer. We conducted semistructured interviews using a purposive sampling method. Fifteen patients at the gynaecologic oncology clinic from January 2014 to April 2015 joined the study. Participants were instructed to read the living will document designed by the Thai National Health Security Office (NHSO) and asked about 3 aspects; awareness of and attitude towards living wills, comprehension of the document, and decision-making. Final codes were analysed using investigator and data triangulation methods along with content analysis. All participants were in the early stages of cancer. Five women were diagnosed with breast cancer, 7 with cervical cancer, and 3 with ovarian cancer. None of them had heard of living wills before. Three themes emerged; 1) Participants felt overwhelmingly positive about the idea of making an AD with a living will. 2) The document was too complicated for participants. 3) Past experiences about death and terminal illness played a major role in decision-making regarding AD. In conclusion, larger scale assessment of $\mathrm{AD}$ in Thailand is recommended. Living wills may be useful tools for making AD in women with cancer but they need to be simplified.
\end{abstract}

Keywords: Advance directive, living will, qualitative research, cancer, palliative care

\section{Introduction}

A living will is a form of Advance Directive (AD), a medical agreement to express a person's health care preferences should they become incapacitated [1]. It is to ensure that the person's wishes and their autonomy are respected [2]. Apart from their autonomy, it could also prevent medical futility that mostly occurs among terminally ill patients [1-8]. While most of their wishes are to have a high quality of life, to be independent and to complete their unfinished businesses, only half of the patients are able to communicate their needs to the family members and doctors [9]. Furthermore, health expenditure during terminal states is significantly higher compared with other states of life, up to 31,702 USD in those aged between 65 - 69 years old [10]. In the USA, the Patient Self Determination Act (PSDA) was formed in 1991 to prevent these outcomes. After PSDA implementation, most of the patients who made a living will had their wishes answered and could fulfill their unfinished businesses. The cost of hospital stay for both parties also reduced drastically, emphasising the significance of living wills [11,12]. After the launch in the USA, living wills have expanded into other countries due to its effectiveness [13,14]. In Thailand, 
http://wjst.wu.ac.th

there was a health act legislation in 2007, legalising the use of a living will. However, no practical assessment of living wills has been investigated so far.

Previous studies mainly focused on healthcare providers [15]. Those focused on patients were performed in terminal cases during hospital admission [16-19] and no studies have explored AD in nonterminal and ambulatory patients yet.

This study aims to explore the awareness and attitudes of living wills among Thai women who were diagnosed with cancer and are in their early stage of cancer.

\section{Materials and methods}

\section{Study design}

We conducted semi-structured interviews with fifteen patients at the Gyneocology Clinic in Phramongkutklao Hospital between January 2014 and April 2015. Purposive sampling method was used for various ages, clinical staging, clinical diagnosis, and diverse socioeconomic background. Inclusion criteria were 1) Diagnosis of any malignancies 2) Age over 18 years old 3) Can communicate in Thai. The interviewer (TP) approached the participants and explained the objective of the study then received written informed consent. Each participant then had an individual interview in a private room at the outpatient unit. The guidelines for the interview were derived from a living will document sample 1 designed by The National Health Commission Office (NHCO) of Thailand. All of the interviews were conducted in Thai and were video recorded for nonverbal language interpretation. Conversations were transcribed verbatim along with field notes and audit trails immediately after each session. After demographic data collection, participants were asked if they had ever heard of a living will then were given the document to read. TP answered and discussed any questions and gave further explanation to the participants until no questions arose. The session continued after the participants had finished reading the document. Three aspects were explored: awareness of and attitudes towards living wills, comprehension of medical terminology in the document and decision making relating to treatment of choice in the document. The interview lasted 30 to $60 \mathrm{~min}$ for each session. For the translation process, we discussed the quotes and their implicated meanings with a native English speaker. We decided to leave grammatical errors and erroneous phrases as they were to reflect how the participants, all of whom have different socioeconomic and educational background, replied during the interviews.

\section{Data analysis}

To make this work more rigorous, we used the investigator triangulation method along with the data triangulation method. Codes were created independently by the researchers. Any discrepancies were discussed between the authors before final codes conception. Codes were then analysed using a content analysis approach and were described along with verbatim quotes from the participants. We gathered the data until we reached saturation point in which no new concepts emerged.

\section{Ethical consideration}

The Ethics Committee Board of the Institutional Review Board of the Royal Thai Army Medical Department (IRBTA) approved this study. Participation was voluntary and did not affect their treatment in any way.

\section{Results}

\section{Participant characteristics}

We interviewed fifteen patients (aged 27 - 68 years old) all of whom had different education and socioeconomic backgrounds. The majority $(80 \%)$ of them were married, received secondary level of education $(60 \%)$. Participants had diverse diagnoses of cancer and different clinical staging (7 with cervical cancer, 5 with breast cancer, and 3 with ovarian cancer), all of whom were totally independent with a score of 20 using the Modified Barthel Activity of Living Index (MBAI) (Table 1). 
http://wjst.wu.ac.th

Table 1 Participant characteristics.

\begin{tabular}{|c|c|c|}
\hline Characteristics & $\mathbf{N}$ & $\%$ \\
\hline \multicolumn{3}{|l|}{ Age in years } \\
\hline Mean $+/-$ SD & $44.0+/-9.2$ & \\
\hline \multicolumn{3}{|l|}{ Gender } \\
\hline Female & 15 & 100.00 \\
\hline \multicolumn{3}{|l|}{ Marital status } \\
\hline Single & 2 & 13.30 \\
\hline Married & 12 & 80.00 \\
\hline Widowed & 1 & 6.70 \\
\hline \multicolumn{3}{|l|}{ Education } \\
\hline Primary & 1 & 6.70 \\
\hline Secondary & 9 & 60.00 \\
\hline Tertiary & 5 & 33.30 \\
\hline \multicolumn{3}{|l|}{ Diagnosis } \\
\hline \multicolumn{3}{|l|}{ Breast cancer } \\
\hline Stage II & 5 & 33.30 \\
\hline \multicolumn{3}{|l|}{ Cervical cancer } \\
\hline Stage I & 2 & 13.30 \\
\hline Stage II & 4 & 26.67 \\
\hline Stage III & 1 & 6.70 \\
\hline \multicolumn{3}{|l|}{ Ovarian cancer } \\
\hline Stage I & 3 & 20.00 \\
\hline \multicolumn{3}{|l|}{ Living will awareness } \\
\hline No & 15 & 100.00 \\
\hline The Modified Barthel Activities of Daily Index (MBAI) & & \\
\hline Totally independent $($ score $=20)$ & 15 & 100.00 \\
\hline
\end{tabular}

Living will awareness

All of the participants had never heard of a living will before. When asked about the document, 3 of them thought it was a will; an official statement of what a person has decided should be done with their money and property after their death, whereas 4 of them thought it was a life insurance. This misunderstanding might partially be caused by the Thai word, "Pinaikam Chi-vit" (the life insurance/will), which was a misleading translation.

"Living will... Is it a life insurance?"

Pt. 2

Three themes emerged (Table 2). 
http://wjst.wu.ac.th

Table 2 Themes and quotes.

\begin{tabular}{|c|c|c|c|}
\hline Primary themes & Subthemes & Codes & Verbatim quotes \\
\hline $\begin{array}{l}\text { Participants felt overwhelmingly } \\
\text { positive about the idea of making } \\
\text { an } \mathrm{AD} \text { with a living will }\end{array}$ & $\begin{array}{l}\text { - Expressing } \\
\text { autonomy }\end{array}$ & - Autonomy & $\begin{array}{l}\text { My family would know } \\
\text { what I want. }\end{array}$ \\
\hline (15 out of 15 participants). & $\begin{array}{l}\text { - Good method to } \\
\text { communicate }\end{array}$ & - Communication & $\begin{array}{l}\text { My children won't } \\
\text { have the guts to make a } \\
\text { call if I becoming that } \\
\text { [terminal]." }\end{array}$ \\
\hline $\begin{array}{l}\text { The document was too } \\
\text { complicated for participants }\end{array}$ & $\begin{array}{l}\text { - Too many } \\
\text { details }\end{array}$ & - Treatment of choice & $\begin{array}{l}\text { "I don't even get half } \\
\text { of it. Way too long." }\end{array}$ \\
\hline ( 9 out of 15 participants). & - Too complex & & \\
\hline \multirow[t]{2}{*}{$\begin{array}{l}\text { Past experiences about death and } \\
\text { terminal illness play a major role } \\
\text { in decision-making regarding AD } \\
\text { (12 out of } 15 \text { participants). }\end{array}$} & $\begin{array}{l}\text { - Negative past } \\
\text { experiences }\end{array}$ & - Direct & $\begin{array}{l}\text { "I don't want to have } \\
\text { another intubation. It } \\
\text { hurt so much and I } \\
\text { couldn't make a noise. } \\
\text { Never (firmly). }\end{array}$ \\
\hline & & - Indirect & $\begin{array}{l}\text { "I remember when my } \\
\text { mum couldn't eat and } \\
\text { she had to have a tube } \\
\text { shoved down her nose. } \\
\text { She looked so } \\
\text { miserable. I don't want } \\
\text { that." }\end{array}$ \\
\hline
\end{tabular}

\section{Participants felt overwhelmingly positive about the idea of making an AD with a living will}

After reading the document, 14 of them had positive attitudes toward the document.

"It's all me (laugh); how I want to live or die. The one who thought this up really knows me."

One participant felt emotionally negative regarding to the document but added that it helped her reflect about her illness in a what-if situation. This could be seen as a positive attitude toward the document as well.

"It makes me feel kinda sad, depressing, even. But it also got me to think about myself. What would I do if I were...in that [terminal] state?"

After the interview, 3 participants even requested to make their living will, emphasising that it is a good way to communicate with their doctor and family. 
http://wjst.wu.ac.th

"It is good, y' know? My family would know what I want. My children won't have the guts to make a call if I becoming that [terminal]."

However, due to the document's complexity and multitude of decision-making choices, another theme rose.

The document was too complicated for participants

Nine participants stated that the document was too complicated thus making it hard to make any choices regarding their treatment of choice even after a full explanation from the interviewer.

[When asked about CPR] 'I don't know. I don't have any experience with that [CPR], you know? And the document that I read earlier? I don't even understand most of that. Way. Too Long. (chuckle)."

They even mistook some of the content.

"Is it like when my pop wants to donate his body [as a cadaver for medical study]?"

Interestingly, when asked about medical terminologies, medical procedures and decision-making in the document, 11 of the participants related to their past experiences, directly or indirectly, rather than from the document they just read.

[When asked about definition of NG feeding] [used to do it herself] "It's a tube. You feed them through here [point]. See how they make a hole here? Then I push the liquid food through that",

This leads to the following third theme.

Past experiences about death and terminal illness play a major role in decision-making regarding $\mathrm{AD}$

When asked about making an $\mathrm{AD}$, the answers were divided into 2 groups; those who already made an $\mathrm{AD}$ or intend to (11) and those who does not want to make an $\mathrm{AD}$ (4). Five participants even made a verbal plan with their relatives.

"I had a dinner with my son and said "Look, if I am not getting better, just let me go, ok? I don't want to be a burden to you and I don't want you to remember your ma as getting hooked on tubes and machines and stuff.",

All of the participants in this group either had a direct or indirect negative experiences regarding terminal illness from their past. One of them even reflected how she related her mother's illness to herself.

“My mother was very sick. Alzheimer's. She was so delirious that her nurses had to tie her up to a hospital bed. After she was intubated, she was...kept....alive..by us. [long pause] I don't want that for myself." 
http://wjst.wu.ac.th

They emphasised not wanting those procedures performed on them and wanting to avoid that at all costs; any procedures perceived as painful or directly invaded the body such as intubation or nasogastric tube feeding.

[When asked about treatment of choices in the document] "I can't think of anything right now but no [NG] tube feed!! It was so painful. Ohhh the pain back then. It was so dreadful."

[Have experience of intubation] "I tried to make a noise but nothing came out. It was like there was a huge bubble wrapping up around you and you were about to burst. So I.....never ever want to go through that again." (looks determined)

The second group, all of whom were patients that did not have a clear understanding regarding their illness or prognosis, did not think about an Advance Care Plan (ACP) at all.

"Nope (shaking head). I don't want to think about it...don't wanna. Because it's too stressful..depressing."

Pt. 9

They felt that it was not the right time to have a talk about AD.

"Don't think about it at all. Even after reading this, I still don't want to [make an AD]. Too soon for me."

When probed further, it turned out that their lack of understanding of the disease and prognosis was partly due to the improper truth-telling process from the physicians or the lack thereof.

[When asked about her diagnosis] "I was sitting in that room then my doctor called my niece to go outside. They had a very long talk. I knew that it must not be good at all. Especially when he [her doctor] didn't have the guts to tell me himself."

In both groups, when asked to think about a hypothetical situation where their disease is deemed incurable or they become comatose, 9 participants requested the Do Not Resuscitate (DNR) option while the other 6 opted for a proxy (Table 3).

Table 3 Participants' decision during terminal stage.

\begin{tabular}{lrcc}
\hline & & \multicolumn{3}{c}{ Proxy } \\
\cline { 3 - 4 } & DNR & Doctor & Relative \\
\hline Decision & 9 & 5 & 1 \\
\hline
\end{tabular}

DNR

"If I were to croak, just let me die naturally. I want to pass away without any suffering." 
http://wjst.wu.ac.th

\section{Proxy}

Of 5 participants, 4 of them would leave the decision to their doctor and the other one to her family carer, her niece.

"I would leave all of the decisions to my niece. Whatever happens, happens. Let her make the call."

"I trust in my doctor's judgement completely. He knows best."

\section{Discussion}

From this study, the most consistent finding was that participants had overwhelmingly positive attitudes toward living wills. They saw the document as a tool to deliver their wishes, prevent unnecessary suffering and help reflect upon their illness. They also believed a living will to be one of the effective methods to express their autonomy in a written, viable form rather than a verbal consent that may or may not be fulfilled at the terminal moment which correlates to previous studies [4-6]. However, the second theme demonstrated the challenge of making an $\mathrm{AD}$ that persists. For comprehension of the document, almost all (11) of the participants used their past experiences as references. This might be because the document was too complicated and covered many complex issues; medical terminologies, multiple treatment of choice without a proper explanation. Hence participants could not understand all of the content, and make the medical decisions.

[When probed to explain about one of the medical terminologies] "I know only some words in there! (sound upset) but you must explain it too! I just get only some part of it, not the whole bloody thing "kay!!"

To make the living will document more effective, multiple sessions and interactive discussions with a resource person such as doctors are recommended [7,8,14]. The document also needs to be simplified in order to reach a larger section of the population as well. Additionally, since about one-third [5] of the participants relied on their doctor their choices during the terminal phase, interventions to improve doctors' understanding and eagerness to initiate a talk about AD is also noteworthy. Previous works show that doctors who understand the concept of AD tend to discuss it with their patients and the patients will have higher rate of making an $\mathrm{AD}[4,7,8,20]$.

Regarding past experiences and the decision-making regarding $\mathrm{AD}$, negative direct and indirect experiences had a huge impact on participants' decision. One explanation to this phenomenon is how participants perceive their disease. Participants that have a clear understanding of their treatment plan and prognosis could all talk about $\mathrm{AD}$, emphasising that it is to voice their autonomy.

"My husband could not make a call [being a proxy] so I think this is a good way for him to know what I actually need. Or else he may regret his choice forever after I die.

On the other hand, those who do not fully understand about their disease and prognosis tend to avoid talking about AD. It may be caused by a lack of clear pictures of what could happen to them afterward from the improper truth-telling process. This lack of understanding could also explain why some (5) of the participants decided to leave all of the treatment choices to their proxy. They perceived that proxies have more knowledge about the disease than themselves and would be a better judge for their treatment. This could also partially be caused by Thai culture that has high power distance [21] where paternalistic relationship between patients and doctors are still abundant and accepted. 
http://wjst.wu.ac.th

"If he [her doctor] told me to do it like one two three [treatment options] then that would be the best choice, no? Who am I to doubt my doctor?

"I am a chef so I know everything in the kitchen. And she's my doctor. How could I not trust her when we both are professional in our field? My life is in her hands."

This finding reflects the importance of proper truth-telling. If patients do not have a proper understanding, their autonomy or importance of $\mathrm{AD}$ may have been overlooked.

In conclusion, none of the participants had heard of a living will before. However, all of them had very positive attitudes toward the document. Thus, assessing this in a larger scale is noteworthy. These findings reflect a need for strategies to promote living will awareness. Public relations or help from the media and education resources may help promoting living will awareness in Thailand.

\section{Recommendations}

\section{Larger scale assessment}

To our knowledge, this is the first study to explore living will awareness and attitudes in women with cancer in Thailand. A study in a larger population will help us grasp a better understanding of the national situation and may lead to proper interventions that coincide with the latest national strategy that puts palliative care as one of the national policies [22].

\section{Contents of the living will document}

The document needs to be simplified so that readers could have a better understanding of the content. Due to the complexity of the living will, multiple sessions with interactive explanations from medical personnel covering complicated topics such as medical terminologies and medical procedures also prove to be beneficial $[13,14,20]$. Furthermore, other simplified material could be used as a substitute for the official document; 5 wishes [23], or Samut-bao-jai (Baojai book) [24] are other examples that may reach a larger population.

\section{Timing for ACP and AD}

In patients with early diagnosis of cancer, a talk about making a living will might be overlooked because they may still aim for a curative goal, find it too early, or too stressful to talk about death or making an $\mathrm{AD}[8,20]$. Cultural influences in Thailand that perceive a talk about death as a sensitive issue is also another contributing factor $[21,25,26]$. This finding supports previous studies that initiating the AD requires multiple factors; patient, family, and doctor [27,28].

However, it does not mean that living wills should be totally ignored. Physicians need to individually assess the patient regarding the proper time to talk about it. Deteriorating health or living with cancer for a long period also increases eagerness to make a living will [29-32] so these other factors might be considered when timing the ACP.

\section{Strengths}

To our knowledge, this study is the first qualitative research in Thailand that delves into living will awareness and attitudes in women who have early stage cancer. The interviews were conducted in an ambulatory setting, where early clinical stage of cancer patients gathered. Their perception regarding AD also differed greatly from those who are in the terminal state or being admitted as in previous studies [16$18]$.

\section{Limitations}

Our study had several limitations. First, the interviews were conducted in a large tertiary care hospital in the capital city. Participants' answers may differ from another setting such as 
http://wjst.wu.ac.th

secondary care hospitals due to different socioeconomic factors and disease background. Second, despite using semi-structured interview guidelines, they were all one-session interviews. Important issues may have been missed or not explored thoroughly. Further mutual relationship between participants and the interviewer with multiple session interviews may be needed to delve more deeply regarding complicated and sensitive issues. In addition, this study did not include those who were already aware of or had already made a living will; thus, we cannot deduce anything from this missing group. Finally, just like any other qualitative research, participants were purposely selected and contextualised. Further study is recommended for generalisation of this work.

\section{Conclusions}

Living wills prove to be a useful tool for making $\mathrm{AD}$ in women with cancer but need to be simplified. Larger scale assessment of AD in Thailand is recommended.

\section{Acknowledgements}

The authors would like to express our gratitude to the women who participated in this study.

\section{References}

[1] S Sahm, R Will and G Hommel. Attitudes towards and barriers to writing advance directives amongst cancer patients, healthy controls, and medical staff. J. Med. Ethics 2005; 31, 437-40.

[2] S Sahm, R Will and G Hommel. What are cancer patients' preferences about treatment at the end of life, and who should start talking about it? A comparison with healthy people and medical staff. Support Care Cancer 2005; 13, 206-14.

[3] S Sahm, R Will and G Hommel. Would they follow what has been laid down? Cancer patients' and healthy controls' views on adherence to advance directives compared to medical staff. Med. Health Care Philos. 2005; 8, 297-305.

[4] N Evans, C Bausewein, A Meñaca, EV Andrew, IJ Higginson, R Harding, R Pool and M Gysels. A critical review of advance directives in Germany: Attitudes, use and healthcare professionals' compliance. Patient Educ. Couns. 2012; 87, 277-88.

[5] M Escher, TV Perneger, S Rudaz, P Dayer and A Perrier. Impact of advance directives and a health care proxy on doctors' decisions: A randomized trial. J. Pain Symptom Manag. 2014; 47, 1-11.

[6] CSantonocito, G Ristagno, A Gullo and MH Weil. Do-not-resuscitate order: A view throughout the world. J. Crit. Care 2013; 28, 14-21.

[7] MI Tamayo-Velázquez, P Simón-Lorda, R Villegas-Portero, C Higueras-Callejón, JF GarcíaGutiérrez, F Martínez-Pecino and IM Barrio-Cantalejo. Interventions to promote the use of advance directives: An overview of systematic reviews. Patient Educ. Couns. 2010; 80, 10-20.

[8] KDP Puente, JL Hidalgo, MJ Herráez, BN Bravo, JO Rodríguez and VG Guillén. Study of the factors influencing the preparation of advance directives. Arch. Gerontol. Geriatr. 2014; 58, 20-4.

[9] RE Rakel and P Storey. Care of dying Patient. In: RE Rakel. Textbook of Family Practice. $7^{\text {th }}$ ed. Saunders Elsvier, Philadelphia, 2007, p. 107-126.

[10] Australian Government. Costs of Death and Health Expenditure. Available at: http://www.pc.gov.au/inquiries/completed/ageing/technicalpapers/technicalpaper13.pdf, accessed January 2017.

[11] J Stjernsward, KM Foley and FD Ferris. Integrating palliative care into national policies. J. Pain Symptom Manag. 2007; 33, 514-20.

[12] J Stjernsward, KM Foley and FD Ferris. The public health strategy for palliative care. J. Pain Symptom Manag. 2007; 33, 486-93.

[13] ML Rurup, BD Onwuteaka-Philipsen, AVD Heide, GVD Wal and DJ Deeg. Frequency and determinants of advance directives concerning end-of-life care in the Netherlands. Soc. Sci. Med. 2006; 62, 1552-63.

[14] C Sinclair, KA Auret, SF Evans, F Williamson, S Dormer, A Wilkinson, K Greeve, A Koay, D 
http://wjst.wu.ac.th

Price and F Brims. Advance care planning uptake among patients with severe lung disease: A randomised patient preference trial of a nurse-led, facilitated advance care planning intervention. BMJ Open 2017; 7, e013415.

[15] S Sittisombut, C Maxwell, EJ Love and C Sitthi-Amorn. Physicians' attitudes and practices regarding advanced end-of-life care planning for terminally ill patients at Chiang Mai University Hospital, Thailand. Nurs. Health Sci. 2009, 11, 23-8.

[16] S Sittisombut, EJ Love and C Sitthi-Amorn. Attitudes toward advance directives and the impact of prognostic information on the preference for cardiopulmonary resuscitation in medical inpatients in Chiang Mai University Hospital, Thailand. Nurs. Health Sci. 2005; 7, 243-50.

[17] S Sittisombut, EJ Love and C Sitthi-Amorn. Cardiopulmonary resuscitation performed in patients with terminal illness in Chiang Mai University Hospital, Thailand. Int. J. Epidemiol. 2001; 30, 8968.

[18] S Sittisombut, C Maxwell, EJ Love and C Sitthi-Amorn. Effectiveness of advance directives for the care of terminally ill patients in Chiang Mai University Hospital, Thailand. Nurs. Health Sci. 2008; 10, 37-42.

[19] S Sittisombut and S Inthong. Surrogate decision-maker for end-of-life care in terminally ill patients at Chiang Mai University Hospital, Thailand. Int. J. Nurs. Pract. 2009; 15, 119-25.

[20] A Lovell and P Yates. Advance Care Planning in palliative care: A systematic literature review of the contextual factors influencing its uptake 2008-2012. Palliat. Med. 2014; 28, 1026-35.

[21] L Meeuwesen, AVD Brink-Muinen and G Hofstede. Can dimensions of national culture predict cross-national differences in medical communication? Patient Educ. Couns. 2009; 75, 58-66.

[22] U Milintangkul. National Policy on Palliative Care in Thailand. Available at: http://en.nationalhealth.or.th/sites/default/files/NationalPolicyonPCare2015_09_17.pdf, accessed December 2016.

[23] About Five Wishes. Available at: https://www.agingwithdignity.org/five-wishes/about-five-wishes, accessed December 2016.

[24] Baojai. Available at: http://www.budnet.org/sunset/baojai, accessed December 2016.

[25] N Sowattanangoon, N Kotchabhakdi and KJ Petrie. The influence of Thai culture on diabetes perceptions and management. Diabetes Res. Clin. Pract. 2009; 84, 245-51.

[26] T Walter. Historical and cultural variants on the good death. BMJ 2003; 327, 218-20.

[27] K Almack, K Cox, N Moghaddam, K Pollock and J Seymour. After you: Conversations between patients and healthcare professionals in planning for end of life care. BMC Palliat. Care 2012; 11, 15.

[28] JJ Rhee, NA Zwar and LA Kemp. Why are advance care planning decisions not implemented? Insights from interviews with Australian general practitioners. J. Palliat. Med. 2013; 16, 1197-204.

[29] JW Mack, A Cronin, NL Keating, N Taback, HA Huskamp, JL Malin, CC Earle and JC Weeks. Associations between end-of-life discussion characteristics and care received near death: A prospective cohort study. J. Clin. Oncol. 2012; 30, 4387-95.

[30] JW Mack, JC Weeks, AA Wright, SD Block and HG Prigerson. End-of-life discussions, goal attainment, and distress at the end of life: Predictors and outcomes of receipt of care consistent with preferences. J. Clin. Oncol. 2010; 28, 1203-8.

[31] AJ Brown, MJ Shen, D Urbauer, J Taylor, PA Parker, C Carmack, L Prescott, E Kolawole, C Rosemore, C Sun, L Ramondetta and DC Bodurka. Room for improvement: An examination of advance care planning documentation among gynecologic oncology patients. Gynecol. Oncol. 2016; 142, 525-30.

[32] GJ Alano, R Pekmezaris, JY Tai, MJ Hussain, J Jeune, B Louis, G El-Kass, MS Ashraf, R Reddy, M Lesser and GP Wolf-Klein. Factors influencing older adults to complete advance directives. Palliat. Support Care 2010; 8, 267-75. 